all of the books contain a reasonable introduction to Fraunhofer diffraction (although Welford says little on the theory of diffraction gratings), but the depth of coverage of Fresnel diffraction shows greater variation. Welford assigns the topic only two pages, omitting, for example, the Fresnel zone plate and the Cornu spiral. Möller's treatment is the most detailed.

The best account of interference is perhaps provided by Smith and Thomson, although some interferometers might have been better omitted, rather than discussed so briefly. Fourier transform spectroscopy, now a standard technique in the infrared, is mentioned by Smith and Thomson and by Welford, whereas it is dealt with in some depth by Möller. It is a little surprising that Smith and Thomson do not give the technique more space, as their book contains by far the greatest coverage of Fourier theory in general.

The basics of polarization are well treated in all three books, but Welford goes little beyond that. Smith and Thomson move on to give accounts of the transverse and longitudinal electro-optics effects, now used so widely in the optics laboratory, but only Möller proceeds to discuss one of the three basic calculation techniques for handling problems in polarized light: Jones calculus.

All of the authors have something to say on lasers, Smith and Thomson devoting a full chapter to the subject. Möller has surprisingly little on holography, considering the size of his book, whereas Welford gives more detail on holographic interferometry than one might have expected in a short, first-year undergraduate text. In the area of what might be described as modern optics, we have accounts of nonlinear optics in Möller, and Smith and Thomson (the former being the more detailed), integrated optics and acousto-optics in Möller, and optical lightguides in Welford. Möller has included a much more comprehensive treatment of detectors than is provided in the other books, and also has a chapter on scattering.

Which of the books is the most appropriate for a particular undergraduate reader depends on the content of the associated lecture course. The treatment of Fresnel diffraction and aspects of modern optics may be deciding factors.

John Macdonald is a Lecturer in the Department of Physics, University of Reading, Whiteknights, Reading RG6 $2 A F$, UK.

- A Course in Mathematics for Students of Physics, by Paul Bamberg and Shlomo Sternberg, is based on a course taught at Harvard intended for "students with an interest in physics who have a good grounding in onevariable calculus". Published by Cambridge University Press, the work is in two volumes: Vol. 1 is available. Vol.2 is published in May.

\section{Grains to rock}

\author{
Timothy Astin
}

Applled Sedimentology. By Richard C. Selley. Academic: 1988. Pp. 446. Hbk $£ 39.50, \$ 79.50 ; p b k £ 16.95, \$ 34$.

Basics of Physical Stratigraphy and Sedimentology. By William J. Fritz and Johnnie N. Moore. Wiley: 1988. Pp. 371. HbK £40.50, \$45.65; pbk £12.95, $\$ 11.85$.

Exerclses In Physical Stratigraphy and Sedimentology. By William J. Fritz and Johnnie N. Moore. Wiley: 1988. Pp. 221. Pbk £19.85, \$22.35.

Techniques in Sedimentology. Edited by Maurice Tucker. Blackwell Scientific: 1988. Pp. 394. Hbk £39.50, \$89.95; pbk£24.95, \$44.95.

THE study of sedimentary rocks can be loosely divided into two - sedimentology, which encompasses the origin, transport and deposition of rock-forming materials, the effects of depositional environments on rock-type distribution, and of alteration following burial (diagenesis); and stratigraphy, the definition and correlation of rock units, leading to sedimentary basin analysis. Parts of the field have grown rapidly during the past few years, notably diagenesis and more complex methods of basin analysis. Others - such as sediment transport and deposition, methods of analysis, and study of the general nature of sedimentary environments and elements of stratigraphy are comparatively mature.

Three of the textbooks reviewed here confine themselves to well-trodden paths, reproducing much that is to be found elsewhere. The clearest example of reworking is Applied Sedimentology, which is a slightly modified, updated and improved version of Selley's An Introduction to Sedimentology (Academic, 1976), a second edition of which was published in 1982. There is a superficial freshness about the book, enhanced by the spuriously new title, but most of the content is the same. The retention of so much text written before 1975 has occasionally led to absurdities; for example, a newly inserted sentence, "Today the term geosyncline is obsolete", is followed by a lengthy discussion of geosyncline terminology from the old book.

Nonetheless, like its predecessor the 'new edition' has several virtues. All aspects of sedimentary rocks are covered, running from weathering and grain aggregate properties, through transport, depositional structures and environments and subsurface environments, to discussions of the main types of rocks and basins. The material in each section is simplified and easy to read, and the whole gives a helpful introduction for students - as the title to the previous book suggested.

The companion volumes by Fritz and Moore take a very different approach to that adopted by Selley. The books are aimed specifically at students new to the subject, and are intended to provide the foundation for an introductory lecture and practical course. As the title indicates, the material covered in Basics of Physical Stratigraphy and Sedimentology is deliberately limited to stratigraphic principles, and sedimentary rock and structure description. The initial emphasis is on rock description, the account of which is followed by explanation of how transport and depositional processes lead to the structures seen in rocks. The natural next step, discussion of sedimentary environments, is left to other textbooks.

If Basics deals with the sort of material covered in lectures, Exercises has the material you would use in the following practical classes. Specific exercises are given, preceded by comprehensive notes on the topics covered, from rock description, through sedimentary structure analysis, to fence diagrams. I found Exercises, with its insight into how others teach students, the more appealing of the two books; and it made me wonder whether my own department ought to bind its lecture handouts and practicals together into a similar compilation.

In contrast to the other books, Techniques in Sedimentology breaks new ground. It is a response to the growth in use of methods of analysis of sedimentary rocks, especially as applied to diagenesis. The editor set out to cover all the common techniques, including collection of field data, analysis of grain size, optical microscopy, X-ray diffraction, scanning electron microscopy and chemical analysis. The battery of techniques concerned is still growing fast, and the instrumentation list could have been expanded. Obvious (and acknowledged) omissions are ways of measuring porosity and permeability, and all aspects of organic matter analysis (why most geologists consider organic matter as somehow separate from other parts of sedimentary rocks is a mystery). The account of field data collection deals with methods practised by the geologist with notebook, hammer, hand lens and compass, and does not sit easily with the rest of the contributions. Anything more adventurous (sediment peels, box coring and so on) has been deliberately left out.

The summaries of laboratory methods, especially as applied to diagenetic studies, are well done and will be invaluable aids to teaching. All of the techniques presented are likely to be used by the graduate student or applied sedimentologist, and they will find the book extremely useful.

Timothy Astin is a Lecturer in the Postgraduate Research Institute for Sedimentology, University of Reading, Whiteknights, Reading RG6 $2 A B, U K$ 